\title{
Mental illness attitudes and knowledge in non-specialist medical doctors working in state and private sectors
}

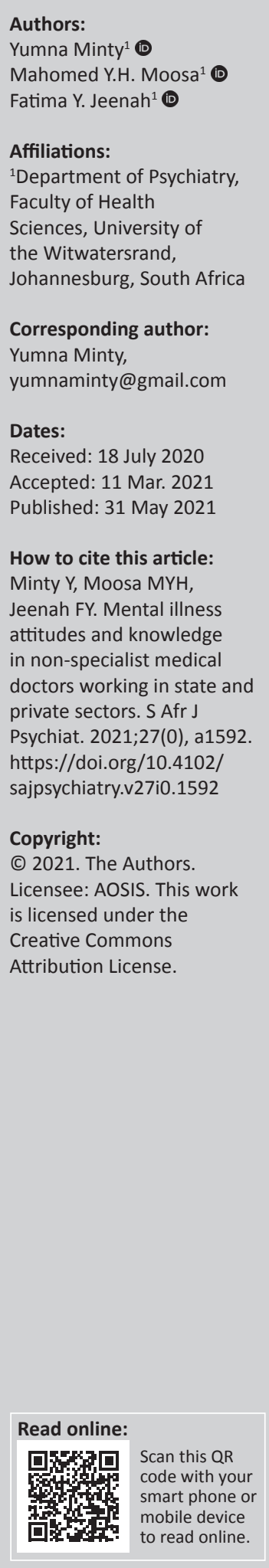

Background: An increasing number of South Africans utilise primary healthcare services (either in the state or private sector) for mental health concerns; hence, there is a need to objectively assess these doctors' attitudes and knowledge of mental illness.

Aim: To investigate aspects of knowledge and attitudes towards mental illness of a group of private and state-employed non-specialist medical doctors.

Method: Doctors in the state sector who were working at a primary healthcare level and who were not working towards, or did not hold, a specialist qualification were considered eligible for the study. Doctors in the private sector who were working as general practitioners and who did not hold a specialist qualification were considered eligible for the study. Data were collected by means of a self-administered questionnaire. A link to the study questionnaire, information about the study, details of the researcher and matters pertaining to informed consent were emailed to potential participants.

Results: Of the 140 practitioners who responded to the survey, 51.4\% $(n=72)$ worked in the state sector, $41.4 \%(n=58)$ worked in the private sector and $7.1 \%(n=10)$ worked in both the state and private sectors $\left(\chi_{1}^{2}=45.31, p<0.010\right)$. The majority $(>50 \%)$ of participants in all three groups had a positive attitude towards mental illness $\left(\chi_{2}^{2}=1.52, p=0.468\right)$. Although there were no significant associations between attitude and socio-demographic characteristics $(p>$ $0.05)$, male SS doctors reported feeling less comfortable when dealing with mentally ill patients $(p=0.015)$; SS doctors who did not have family contact with mental illness were less likely to feel that mentally ill patients did not pose a risk to others $(p=0.007)$, and PS doctors under the age of 35 years were more likely to feel adequately trained to treat mental illness $(p=0.026)$. The majority ( $>50 \%$ ) of participants in all three groups had an adequate level of knowledge of mental illness (modal scores $=10$ ). There were no significant associations between knowledge and socio-demographic characteristics $(p>0.05)$.

Conclusion: Despite the findings of a positive attitude and adequate knowledge of mental illness amongst the participants of this study, it is recommended that more targeted interventions are established to further improve mental health awareness and knowledge of doctors at both undergraduate and postgraduate levels of study.

Keywords: mental illness; stigma; attitudes; mental health literacy; knowledge; doctors; healthcare workers; primary healthcare.

\section{Introduction}

The lifetime prevalence of developing a mental illness, as reported in the South African Stress and Health (SASH) study, is estimated to be about $30 \% \cdot{ }^{1,2}$ This is expected to become higher as the contributions from communicable diseases such as human immunodeficiency virus (HIV), non-communicable diseases, ${ }^{3}$ post-traumatic stress disorder and substance abuse ${ }^{4}$ become apparent.

Mental illness carries more stigma than any other illness, and sufferers are likely to be discriminated against more often and more significantly than the sufferers of other illnesses. ${ }^{5}$ Stigma combines a lack of accurate knowledge, prejudiced and negative attitudes and exclusionary or discriminatory behaviours to form a powerful driver for the social exclusion of persons with mental illness and the infringement of their rights and needs. ${ }^{6}$

Studies looking at mental health professionals' perceptions of mental illness have found predominantly negative attitudes and the endorsement of restrictive and discriminatory practices 
towards the mentally ill. 7,8,9 All of these studies used self-administered questionnaires as a means of evaluating mental illness perceptions, although the actual questionnaires and questions themselves differed amongst studies. A common perception of healthcare personnel, including medical doctors, is that people with mental illness pose a danger to others. ${ }^{10,11,12,13}$ Also expressed by healthcare workers is the belief that the mentally ill are blameworthy and are responsible for their conditions. ${ }^{12,14,15}$ Social distancing by society towards those with mental illness is common. ${ }^{5,10,15}$ It has also been found that certain mental illnesses such as schizophrenia attract more stigma than others., ${ }^{76,17}$

The extent to which patients may benefit from mental illness interventions is dependent not only upon available health resources but also on the level of knowledge and beliefs about mental illness within a community. ${ }^{18}$ Mental health literacy of healthcare workers is particularly important, as poor recognition or misdiagnosis of mental illness leads to delays in or no treatment, with subsequent poorer outcomes for the sufferers. Several studies have attempted to assess the mental health knowledge of healthcare workers and have found these to be poor or inadequate. 9,15,19,20,21 Within South Africa, two studies have assessed nurses, in primary healthcare and psychiatrically trained nursing staff, and found inadequate levels of mental illness knowledge. ${ }^{22,23}$

Negative attitudes and stigma towards sufferers of mental illness form a barrier for treatment-seeking, for prevention of other diseases and conditions and for support in maintaining overall health..$^{24,25,26}$

People with mental illness are at greater risk of premature death compared with those without mental illness ${ }^{27}$ because of poorer access to healthcare for associated physical illnesses ${ }^{28}$ and diagnostic overshadowing. ${ }^{29}$ Lack of accurate knowledge and the prevalence of misinformation contribute to stigmatising attitudes.

Therefore, poor knowledge of mental illnesses may contribute to not only poorer treatment but also perpetuation of stigma and hence reduced access to care, creating a vicious cycle of despair for the mental illness sufferer.

There is a significant body of data confirming that primary healthcare and generalist doctors, amongst other health professionals, hold negative attitudes regarding mental illness. Research also confirms that doctors have difficulty in diagnosing and instituting adequate treatment for mental illnesses. These factors lead to poorer healthcare for those with mental illness. Data on attitudes towards and knowledge of mental illness in South African samples of doctors are lacking, particularly with respect to knowledge of mental illness, hence the need for this study.

\section{Aim and scope of the study}

This study investigated the attitudes and knowledge of non-specialist doctors in the public and private healthcare sectors towards mental illness. The specific objectives were to describe the sociodemographic characteristics, attitudes towards mental illness and knowledge of mental illness of the study populations. A secondary objective was to determine, if any, the factors associated with differences in attitudes and knowledge in doctors working in state and private sectors.

\section{Method}

The study was a cross-sectional study. Doctors in the state sector who were working at a primary healthcare level and who were not working towards, or did not hold, a specialist qualification were considered eligible for the study. Doctors in the private sector who were working as general practitioners and who did not hold a specialist qualification were considered eligible for the study. Participants were not limited to doctors practising in Johannesburg.

\section{Data collection}

Data were collected by means of a self-administered questionnaire. The questionnaire consisted of three parts. The first part of the questionnaire included information on the following: age, gender, number of years practising medicine, area of medical practice (state or private sector), contact with a close family member with mental illness. The second section of the questionnaire consisted of 10 statements describing attitudes towards mental illness in general. This component was developed after looking at other similar studies, which used Likert-scale questionnaires to assess mental illness attitudes. ${ }^{10,30}$ Ten statements covering stigma concepts such as social distance, negative attitudes, stereotyped beliefs and diagnostic overshadowing were compiled and used in the questionnaire. Respondents were asked to grade their level of agreement with the statements using a 5-point Likert scale (strongly agree, agree, uncertain, disagree and strongly disagree). The third section of the questionnaire consisted of 10 questions designed to assess the general knowledge of mental illness. Each question had three possible answer options (correct answer, incorrect answer and an option if the participant was unsure of the answer). This component was developed after perusing published mental illness literacy scales that assessed the general knowledge of mental illness. ${ }^{31,32,33}$ - these scales were not used in their entirety, with the aim of maintaining the brevity of the study questionnaire, so that participants would not find it tedious to complete. The questions were designed to cover factual aspects of mental illness that generalist doctors would likely encounter frequently, such as depression and anxiety, substance use, dementia, personality disorders and treatment non-adherence.

A link to the study questionnaire (an online questionnaire using a freely available online survey platform), information about the study, details of the researcher and matters pertaining to informed consent were emailed to potential participants. Participants accessed the questionnaire through the electronic link and submitted their responses 
electronically. The questionnaire was disseminated to potential participants as follows: (1) by the administrators of professional practitioner bodies including Independent Practitioners Association, the Islamic Medical Association, the General Practitioners Management Group and others; (2) by clinical managers at state facilities (primary healthcare clinics and district hospitals); and (3) by the researcher directly inviting eligible individuals to participate in the study or to extend the invitation to other colleagues. Data collection took place from December 2017 to September 2018. Data responses were originally recorded automatically in an online database and were then manually exported and recorded in a Microsoft Excel spreadsheet.

\section{Data analysis}

Statistical analyses were conducted using Statistica (version 7; www.statsoft.com). Tests with two-tailed probability values and statistical significance were accepted when $\alpha \leq 0.05$. Data were described by means of proportions and percentages and illustrated using tables. Characteristics of the study populations were analysed and compared using chi-square contingency tests for all variables except age distribution. Age distribution was analysed using a generalised linear model (GLZ) with a Poisson error structure because the data set was large.

For the analysis of attitude and knowledge components, responses to statements and questions were scored to obtain numerical values for comparison. The overall attitude of the respondents towards mental illness was determined by allocating numerical values to the responses as follows: strongly agree $=2$, agree $=1$, uncertain $=0$, disagree $=-1$, strongly disagree $=-2$. Certain statements were scored in reverse to reflect accurate portrayal of positive and negative attitudes. The modal score within each group was determined, as this was a representation of the attitude most commonly endorsed within that group. The scoring for knowledge questions was as follows: a correct response had a score of one and an incorrect response had a score of -1. A response of unsure had a score of zero. A higher score indicated a better knowledge of mental illness. Modal scores for answers to all of the questions were obtained. The sum of modal scores for each study group was compared using chi-square tests to determine any statistically significant difference in the three study groups.

Individual responses to each question were then compared using a GLZ model to determine if there were any such significant differences between the study groups. A GLZ model was used to determine if any of the recorded sociodemographic variables influenced differences in responses between the study groups. Wald $\chi^{2}$ outputs were reported for all GLZ analyses and estimates, and s.e. was reported for significant responses.

A GLZ model was used to determine if any of the recorded sociodemographic variables (age, gender, years of practice and having a family member with mental illness) influenced differences in responses between the study groups.

\section{Ethical considerations}

Ethical approval was obtained from the University of the Witwatersrand Human Research Ethics Committee (protocol number M170733). Owing to the nature of the data collection, it was understood that written consent could not be obtained from each participant. An information leaflet with relevant information about consent for study participation was distributed along with the questionnaire, which made participants aware that tacit consent to participate was implied once an individual accessed the questionnaire and began the survey. Participants were informed that they had the option of not continuing with the questionnaire at any point or choosing not to submit their answers. In addition, they were not obliged to answer any question that they did not wish to.

\section{Results}

Of the 140 practitioners who responded to the survey, $51.4 \%$ $(n=72)$ worked in the state sector, $41.4 \%(n=58)$ worked in the private sector and $7.1 \%(n=10)$ worked in the combined state and private sector $\left(\chi_{1}^{2}=45.31, p<0.010\right)$.

\section{Sociodemographic characteristics}

The mean age of the SS group was 34.4 years (range: 23-56 years), which was significantly lower than that of the PS group (44.6 years; range: $29-71$ years) and the SPS group (44.3 years; range: $31-64$ years) (Wald $\chi^{2}=90.73, p<0.010$ ). The majority of participants in the SS group were in the $<35$ year age group $(52.3 \%, n=38)$, between 35 and 45 years in the PS group $(36.2 \%, n=21)$ and between 35 and 45 years in the SPS group $(50 \%, n=5)$ (Table 1$)$. Of note was that $17.2 \%$ $(n=10)$ of participants in the PS group were over 55 years of age compared with only $1.4 \%(n=1)$ in the SS group.

Majority of the participants were male in the PS group (60.3\%, $n=35)\left(\chi^{2}=90.73, p=0.115\right)$ and the SPS group $(80 \%, n=8)$ $\left(\chi^{2}=3.60, p=0.060\right)$, whilst the majority were female in the SS group (66.6\%, $n=48)\left(\chi_{2}^{2}=8.00, p=0.005\right)$ (Table 1). The majority of participants in the SS group were practising for less than 5 years $(40.3 \%, n=28)$, for more than 20 years in the PS group $(34.5 \%, n=20)$ and for between 11 and 15 years in the SPS group $(50 \%, n=5)\left(\chi^{2}=12.96, p=0.044\right)$. Significantly more respondents in the SS group were employed for less than 5 years and significantly fewer for 20 years or more, compared with the other two groups $\left(\chi^{2}=\right.$ 27.71, $p<0.001$ ) (Table 1). There were no statistically significant differences with respect to personal or family contact with mental illness $(p>0.05)$.

\section{Attitudes towards mental illness}

The majority of the participants (> 50\%) in all three groups agreed with the following statements in the questionnaire: 'people with mental illness rarely pose a risk to their families 
TABLE 1: Frequency distribution of sociodemographic variables of the study population.

\begin{tabular}{|c|c|c|c|c|c|c|}
\hline \multirow[t]{2}{*}{ Sociodemographic variable } & \multicolumn{2}{|c|}{ State sector $(n=72)$} & \multicolumn{2}{|c|}{ Private sector $(n=58)$} & \multicolumn{2}{|c|}{ State and private sector $(n=10)$} \\
\hline & $n$ & $\%$ & $n$ & $\%$ & $n$ & $\%$ \\
\hline \multicolumn{7}{|l|}{ Age } \\
\hline$<35$ years & 38 & 52.3 & 8 & 13.8 & 1 & 10 \\
\hline $35-45$ years & 21 & 29.2 & 21 & 36.2 & 5 & 50 \\
\hline $46-55$ years & 11 & 15.3 & 13 & 22.4 & 1 & 10 \\
\hline$>55$ years & 1 & 1.4 & 10 & 17.2 & 2 & 20 \\
\hline \multicolumn{7}{|l|}{ Gender } \\
\hline Male & 24 & 33.3 & 35 & 60.3 & 8 & 80 \\
\hline Female & 48 & 66.6 & 23 & 39.7 & 2 & 20 \\
\hline \multicolumn{7}{|l|}{ Years of practice } \\
\hline$<5$ years & 28 & 40.3 & 0 & 0.0 & 0 & 0 \\
\hline $5-10$ years & 18 & 25.0 & 10 & 17.2 & 2 & 20 \\
\hline $11-15$ years & 16 & 22.2 & 17 & 29.3 & 5 & 50 \\
\hline $16-20$ years & 5 & 6.9 & 10 & 17.2 & 1 & 10 \\
\hline \multicolumn{7}{|c|}{ Family member with mental illness } \\
\hline Yes & 30 & 41.7 & 27 & 46.6 & 4 & 40 \\
\hline No & 35 & 48.6 & 24 & 41.4 & 5 & 50 \\
\hline Unsure & 12 & 16.7 & 5 & 8.6 & 1 & 10 \\
\hline
\end{tabular}

and communities', 'employers should hire a person with a managed mental illness if he or she is the best person for the job', 'I feel that I am adequately trained and have sufficient knowledge to be able to diagnose and initiate treatment in a person with mental illness' and 'I would not mind if a person with mental illness lived next door to me' (Table 2).

The majority of participants (> 50\%) in all three groups disagreed with the following statements posed in the questionnaire: 'most people with mental illness don't try hard enough to get better', 'I sometimes perceive people with mental illness as being weak or lacking in willpower and self-discipline' and 'if a person with mental illness complained of physical symptoms, I would likely attribute this to their mental illness' (Table 2).

The only significant difference found in responses for individual questions was that participants in the SS group were more likely to agree that they were more comfortable treating someone with a physical illness than a mental illness, when compared with the PS group (Wald $\chi_{1}^{2}=15.691$, $p=0.047)$.

The most overall positive attitude towards mental illness was observed in the PS group (total modal score $=11$ ) followed by the SS group (total modal score $=8$ ) and the SPS group (total modal score $=6$ ). The differences between the three groups were not statistically significant $\left(\chi_{2}^{2}=1.52, p=0.468\right)$.

\section{Knowledge of mental illness}

The majority of participants in all three groups (> 50\%) gave the following correct responses to questions in the survey: 'psychotherapy may be the most beneficial intervention in personality disorders', 'someone who has a close family member with depression is at risk of developing depression', 'people with schizophrenia who do not take their treatment regularly most likely do so because they do not recognise that they have an illness', 'people with post-traumatic stress disorder are at high risk for developing alcohol abuse', 'a woman with borderline personality disorder who frequently becomes suicidal because of an ongoing fear is most likely fearful of abandonment' and 'an elderly patient who is brought to the doctor by her family as she has become difficult and unmanageable at home over the past few months, hiding things away and accusing family of stealing things from her, is most likely suffering from dementia' (Table 3).

The majority of the doctors in the SS group (> 50\%) and all of the doctors in the PS group and SPS group responded correctly to the question, which stated that people who have had one episode of depression are most at risk for another episode of depression.

In addition, the majority of doctors in the SS and PS groups (> 50\%) gave correct responses to the following questions: 'a man at the airport who is talking and laughing very loudly, passing money to people and talking about his plans to fly around the world is most likely suffering from mania', 'a woman who has been isolating herself from friends and family and no longer pursues hobbies and interests as before is most likely suffering from depression' and 'mental illness can most often be attributed to chemical imbalances or structural damage to the brain'.

The sum of the modal scores for all three groups was the same, indicating that there was no statistical difference between the knowledge scores of the three groups.

\section{Association between sociodemographic characteristics and attitude and knowledge of mental illness}

The SPS group was excluded from this analysis because of the small sample size. There was no statistically significant difference in the overall attitude towards mental illness between the SS and PS groups with respect to age (Wald $\chi_{1}^{2}=9.564$, $p=0.089$ ), gender (Wald $\chi_{1}^{2}=0.636, p=0.425$ ), duration of 
TABLE 2: Frequency distribution of responses to the attitude statements in the study population.

\begin{tabular}{|c|c|c|c|c|c|c|}
\hline \multirow{2}{*}{$\begin{array}{l}\text { Attitude } \\
\text { statements }\end{array}$} & \multicolumn{2}{|c|}{ State sector $(n=72)$} & \multicolumn{2}{|c|}{ Private sector $(n=58)$} & \multicolumn{2}{|c|}{ State and private sector $(n=10)$} \\
\hline & $n$ & $\%$ & $n$ & $\%$ & $n$ & $\%$ \\
\hline \multicolumn{7}{|c|}{ 1. People with mental illness rarely pose a risk to their families and communities } \\
\hline Strongly agree & 4 & 5.6 & 7 & 12.1 & 0 & 0 \\
\hline Agree & 36 & 50.0 & 32 & 55.2 & 5 & 50 \\
\hline Uncertain & 4 & 5.6 & 3 & 5.2 & 1 & 10 \\
\hline Disagree & 23 & 31.9 & 8 & 13.8 & 4 & 40 \\
\hline Strongly disagree & 5 & 6.9 & 7 & 12.1 & 0 & 0 \\
\hline \multicolumn{7}{|c|}{ 2. I am more comfortable treating someone with a physical illness than a mental illness } \\
\hline Strongly agree & 5 & 6.9 & 3 & 5.2 & 1 & 10 \\
\hline Agree & 47 & 65.3 & 23 & 39.7 & 5 & 50 \\
\hline Uncertain & 2 & 2.8 & 3 & 5.2 & 0 & 0 \\
\hline Disagree & 15 & 20.8 & 24 & 41.4 & 4 & 40 \\
\hline Strongly disagree & 3 & 4.2 & 5 & 8.6 & 0 & 0 \\
\hline \multicolumn{7}{|c|}{ 3. Employers should hire a person with a managed mental illness if he/she is the best person for the job } \\
\hline Agree & 46 & 63.9 & 29 & 50.0 & 5 & 50 \\
\hline Uncertain & 4 & 5.6 & 0 & 0.0 & 1 & 10 \\
\hline Disagree & 2 & 2.8 & 2 & 3.4 & 0 & 0 \\
\hline Strongly disagree & 0 & 0.0 & 1 & 1.7 & 2 & 20 \\
\hline \multicolumn{7}{|c|}{ 4. Healthcare providers have a role in assisting mentally ill patients in becoming active members of their communities } \\
\hline Strongly agree & 33 & 45.8 & 32 & 55.2 & 4 & 40 \\
\hline Agree & 37 & 51.4 & 24 & 41.4 & 5 & 50 \\
\hline Uncertain & 2 & 2.8 & 1 & 1.7 & 1 & 10 \\
\hline Disagree & 0 & 0.0 & 0 & 0.0 & 0 & 0 \\
\hline Strongly disagree & 0 & 0.0 & 0 & 0.0 & 0 & 0 \\
\hline \multicolumn{7}{|c|}{ 5. Most people with mental illness don't try hard enough to get better } \\
\hline Strongly agree & 0 & 0.0 & 1 & 1.7 & 0 & 0 \\
\hline Agree & 13 & 18.1 & 14 & 24.1 & 0 & 0 \\
\hline Uncertain & 7 & 9.7 & 4 & 6.9 & 0 & 0 \\
\hline \multicolumn{7}{|c|}{ 6. I sometimes struggle to feel compassion for a person with mental illness } \\
\hline Strongly agree & 19 & 26.4 & 0 & 0.0 & 0 & 0 \\
\hline Agree & 0 & 0.0 & 16 & 27.6 & 4 & 40 \\
\hline Uncertain & 4 & 5.6 & 4 & 6.9 & 0 & 0 \\
\hline Disagree & 41 & 56.9 & 25 & 43.1 & 2 & 20 \\
\hline Strongly disagree & 8 & 11.1 & 13 & 22.4 & 4 & 40 \\
\hline
\end{tabular}

7. If a person with mental illness complained of physical symptoms (e.g. headache, nausea), I would likely attribute this to their mental illness.

\begin{tabular}{|c|c|c|c|c|c|c|}
\hline Strongly agree & 1 & 1.4 & 0 & 0.0 & 0 & 0 \\
\hline Agree & 18 & 25.0 & 6 & 10.3 & 2 & 20 \\
\hline Uncertain & 6 & 8.3 & 0 & 0.0 & 0 & 0 \\
\hline Disagree & 42 & 58.3 & 43 & 74.1 & 6 & 60 \\
\hline Strongly disagree & 5 & 6.9 & 8 & 13.8 & 2 & 20 \\
\hline
\end{tabular}

8. I feel that I am adequately trained and have sufficient knowledge to be able to diagnose and initiate treatment in a person with mental illness.

\begin{tabular}{|c|c|c|c|c|c|c|}
\hline Strongly agree & 4 & 5.6 & 7 & 12.1 & 0 & 0 \\
\hline Agree & 29 & 40.3 & 29 & 50.0 & 6 & 60 \\
\hline Uncertain & 11 & 15.3 & 4 & 6.9 & 1 & 10 \\
\hline Disagree & 26 & 36.1 & 17 & 29.3 & 3 & 30 \\
\hline Strongly disagree & 2 & 2.8 & 1 & 1.7 & 0 & 0 \\
\hline \multicolumn{7}{|c|}{ 9. I would not mind if a person with mental illness lived next door to me. } \\
\hline Strongly agree & 4 & 5.6 & 9 & 15.5 & 3 & 30 \\
\hline Agree & 58 & 80.6 & 43 & 74.1 & 6 & 60 \\
\hline Uncertain & 5 & 6.9 & 2 & 3.4 & 0 & 0 \\
\hline Disagree & 5 & 6.9 & 4 & 6.9 & 1 & 10 \\
\hline Strongly disagree & 0 & 0.0 & 0 & 0.0 & 0 & 0 \\
\hline
\end{tabular}

10. I sometimes perceive people with mental illness as being weak or lacking in willpower and self-discipline.

\begin{tabular}{lccccc} 
Strongly agree & 0 & 0.0 & 1 & 1.7 & 0 \\
Agree & 17 & 23.6 & 8 & 13.8 & 1 \\
Uncertain & 3 & 4.2 & 3 & 5.2 & 1 \\
Disagree & 41 & 56.9 & 38 & 65.5 & 10 \\
Strongly disagree & 11 & 15.3 & 8 & 13.8 & 5 \\
\hline
\end{tabular}


TABLE 3: The frequency distribution of responses for each of the questions in the study population.

\begin{tabular}{|c|c|c|c|c|c|c|}
\hline \multirow{2}{*}{$\begin{array}{l}\text { Knowledge } \\
\text { statements }\end{array}$} & \multicolumn{2}{|c|}{ State sector group $(n=72)$} & \multicolumn{2}{|c|}{ Private sector group $(n=58)$} & \multicolumn{2}{|c|}{ State and private sector $(n=10)$} \\
\hline & $n$ & $\%$ & $n$ & $\%$ & $n$ & $\%$ \\
\hline \multicolumn{7}{|c|}{ 1. People who have had an episode of depression are most at risk for a psychotic disorder or another episode of depression } \\
\hline Correct & 68 & 94.4 & 58 & 100.0 & 10 & 100 \\
\hline Incorrect & 4 & 5.6 & 0 & 0.0 & 0 & 0 \\
\hline Unsure & 0 & 0.0 & 0 & 0.0 & 0 & 0 \\
\hline \multicolumn{7}{|c|}{ 2. Psychotherapy may be the most beneficial intervention in personality disorders or learning disorders } \\
\hline Correct & 58 & 80.6 & 50 & 86.2 & 9 & 90 \\
\hline Incorrect & 11 & 15.3 & 7 & 12.1 & 1 & 10 \\
\hline Unsure & 3 & 4.1 & 1 & 1.7 & 0 & 0 \\
\hline \multicolumn{7}{|c|}{$\begin{array}{l}\text { 3. A man, at the airport, who is talking and laughing very loudly, passing out money to people and talking about his plans to fly around the world, is most likely suffering fro } \\
\text { mania or delirium }\end{array}$} \\
\hline Correct & 64 & 88.9 & 51 & 87.9 & 10 & 100 \\
\hline Incorrect & 8 & 11.1 & 6 & 10.3 & 0 & 0 \\
\hline Unsure & 0 & 0.0 & 1 & 1.7 & 0 & 0 \\
\hline Correct & 57 & 79.2 & 47 & 81 & 7 & 70 \\
\hline Incorrect & 14 & 19.4 & 9 & 15.5 & 2 & 20 \\
\hline Unsure & 0 & 0.0 & 2 & 3.4 & 1 & 10 \\
\hline
\end{tabular}

5. People with schizophrenia who do not take their treatment regularly, most likely do so because they do not recognise that they have an illness or they believe that medication is ineffective

$\begin{array}{lcccccc}\text { Correct } & 49 & 68.1 & 45 & 77.6 & 7 & 70 \\ \text { Incorrect } & 21 & 29.2 & 12 & 20.7 & 3 \\ \text { Unsure } & 2 & 2.7 & 1 & 1.7 & 0\end{array}$

6. People with post-traumatic stress disorder are at high risk of developing dementia or alcohol abuse

$\begin{array}{lcccccc}\text { Correct } & 57 & 79.2 & 44 & 75.9 & 8 & 80 \\ \text { Incorrect } & 13 & 18.1 & 13 & 22.4 & 2 \\ \text { Unsure } & 2 & 2.7 & 1 & 1.7 & 0\end{array}$

7. A woman with borderline personality disorder who frequently becomes suicidal because of an ongoing fear is most likely fearful of abandonment or gaining weight

$\begin{array}{lcccccc}\text { Correct } & 70 & 97.2 & 56 & 96.6 & 8 & \\ \text { Incorrect } & 2 & 2.8 & 0 & 0.0 & 2 & 20 \\ \text { Unsure } & 0 & 0.0 & 2 & 3.4 & 0\end{array}$

8. A woman who has been isolating herself from friends and family and no longer pursues hobbies and interests as before is most likely suffering from generalised anxiety disorder or depression

Correct 65

Incorrect 7

$\begin{array}{lll}90.3 & 49 & 84.5\end{array}$

$\begin{array}{lll}9.7 & 9 & 15.5\end{array}$

Unsure 0.0

84.5
15.5 0.0

9. Mental illness can most often be attributed to chemical imbalances or structural damage to the brain or poor self-control

$\begin{array}{lcccccc}\text { Correct } & 70 & 97.2 & 55 & 94.8 & 10 \\ \text { Incorrect } & 2 & 2.8 & 3 & 5.2 & 0 \\ \text { Unsure } & 0 & 0.0 & 0 & 0.0 & 0\end{array}$

10. An elderly patient is brought to the doctor by her family as she has become difficult and unmanageable at home over the past few months, hiding things away and accusing family of stealing things from her. She is most likely suffering from dementia or delusional disorder

\begin{tabular}{lcccccc} 
Correct & 59 & 81.9 & 50 & 86.2 & 8 & 12.1 \\
Incorrect & 12 & 16.7 & 7 & 1 & 10 \\
Unsure & 0 & 0.0 & 0 & 0.0 & 1 \\
\hline
\end{tabular}

practice (Wald $\chi_{1}^{2}=0.292, p=0.999$ ) and having a family member with mental illness (Wald $\chi_{1}^{2}=3.248, p=0.197$ ).

There were also no significant associations between overall knowledge score between the SS and PS groups and any of the sociodemographic variables $(p>0.05)$, as well as no significant influences of sociodemographic variables on differences in individual responses to any of the knowledge questions $(p>0.05)$.

\section{Discussion}

\section{Attitudes towards mental illness}

The study found that the overall attitude towards mental illness of both SS and PS doctors was positive. This is similar to the findings of published international studies. $^{34,35,36,37}$

In one such study, Wang et al..$^{38}$ found that over $80 \%$ of study respondents (who were Chinese non-psychiatric hospital doctors) felt that they had a responsibility towards their patients in managing their psychological distress. To the best knowledge of the researchers, there are no published studies amongst non-specialist medical doctors working in South Africa. However, Eksteen et al. ${ }^{39}$ found that psychiatrists had the least stigmatising attitudes when compared with preclinical and post-clinical medical students. Mausling et al. ${ }^{40}$ showed that second-year medical students had positive attitudes towards psychiatric illness and psychiatry, whilst Dube et al. ${ }^{23}$ demonstrated that nurses working in primary 
healthcare clinics were positive about the management of psychiatric patients. Studies have also shown positive attitudes in other healthcare workers, such as medical and nursing students ${ }^{41}$ and nurses, social workers and healthcare assistants. ${ }^{42}$ Similar to this study, it appears from the literature that doctors and other healthcare professionals exhibit positive attitudes towards people with mental illness.

However, there is also a significant body of literature, which shows that doctors have negative attitudes towards mental illness. ${ }^{11,13,43,44}$

One such review, ${ }^{36}$ looking at stigma and discrimination towards mental illness in healthcare professionals found negative attitudes in psychiatrists, nurses, psychologists and medical students; it appeared that the most negative attitudes were described in psychologists. It was also found that chronically ill patients with more hospital admissions were viewed more negatively than patients with milder symptoms. In a South African study, Jury ${ }^{45}$ described negative attitudes towards mental illness in specialist doctors practising in state sector teaching hospitals. In addition, a study of South African nurses by Mavundla et al. $^{46}$ found that participants held mainly negative attitudes towards the mentally ill.

The positive attitudes found in this study could have a number of explanations. It may have been partly as a consequence of improved training and exposure to psychiatry at the undergraduate level, and exposure to psychiatric patients during the internship period..$^{47}$ In addition, there is increasing recognition that the contribution of mental illness to the global disease burden is on the rise ${ }^{48}$ with a consequence of this being that healthcare workers have increased exposure to mental illness and thus may have more positive perceptions. With mental health issues such as the Life Esidimeni tragedy and the recent suicides of prominent figures being widely covered in the mainstream and social media, awareness and advocacy for mental health has improved. This has likely led to a more sympathetic stance towards mental illness amongst doctors and in other sectors of the general population. Mental illness is also on the rise within the medical profession, with recent statistics showing a considerable prevalence in doctors (at the time of writing this article, statistics for mental illness in South African doctors were not available). ${ }^{49,50}$

This may be another contributing factor to positive attitudes, as doctors may be more likely to have a favourable opinion of mental illness if they have personally experienced such symptoms.

Although the difference was not statistically significant, this study found that SS doctors were slightly less positive towards mental illness than their PS counterparts. Similar findings have been reported in other studies., ${ }^{7,51}$ Jury's $^{45}$ study of specialist doctors practising in South African state sector teaching hospitals described negative attitudes towards mental illness, in particular towards schizophrenia and borderline personality disorder. There are, however, published studies with contrasting findings. ${ }^{15,52,53}$

The less positive attitude amongst SS doctors may be because of inadequate exposure to mental illness because of a lack of integration of mental healthcare at primary healthcare level, a demanding workload and a tendency to focus consultations on physical complaints with less time devoted to mental health complaints. In addition, as the SS doctors in this study were generally younger and less experienced than the PS doctors, it is likely that age and lesser experience contributed towards less positive attitudes, as in other studies. ${ }^{11,54}$ Studies have shown that increased exposure to mentally ill people leads to more positive attitudes. ${ }^{55,56,57}$ It is also likely that PS doctors are more open to advocating for their mentally ill patients because of the lesser demands and time constraints of their work as compared with state-employed doctors. Within private practice, it is easier to develop long-lasting and enduring doctor-patient relationships, as patients most often consult with the same doctor multiple times. This is unlike the state sector, where many doctors work in a single department and doctors rotate through different units, hospitals or clinics, meaning that they often do not consult regularly with the same patient. This fragmented relationship may exacerbate feelings of social distance and contribute to less positive attitudes towards patients with mental illness.

\section{Sociodemographic variables associated with attitudes towards mental illness}

This study found that the factors of age, gender, duration of practice and having a family member with mental illness were not significantly associated with overall attitudes towards mental illness. Similarly, Sujaritha et al..$^{52}$ and Sri et al. ${ }^{53}$ reported that gender and level of qualification did not influence mental illness attitudes, whilst Vistorte et al. ${ }^{58}$ found that gender, age, training and years of experience did not hold any association with stigmatising attitudes.

This is contrary to the findings of other published studies, which have reported both positive and negative associations with demographic characteristics. Female doctors have been found to be more positive and much less stigmatising than male doctors. ${ }^{45,59,60,61}$ Stuber et al. ${ }^{62}$ noticed that younger female mental health professionals were less stigmatising than older male professionals. Ewalds-Kvist et al. ${ }^{61}$ reported that even though older individuals were more open-minded towards mentally ill people, they were less likely to be supportive of community psychiatric services and integration. Those with more clinical experience ${ }^{63}$ or a family member or friend with mental illness ${ }^{7,11}$ were more sympathetic towards the mentally ill. However, Chandramouleeswaran et al. ${ }^{55}$ found that personal contact with an individual with a psychiatric condition did not increase the positivity of mental illness attitudes.

Within available literature, the overall impression is that there is no consistent sociodemographic predictor of mental illness 
attitudes as the relationship between variables and attitudes differs across studies, suggesting that these interactions may be complex and multifaceted. The interplay between demographic factors and cultural influences is also likely to play a role in how mentally ill people are viewed by others.

\section{Knowledge of mental illness}

The study found that doctors had adequate knowledge of mental illness, as evidenced by the high modal scores. Similar findings have been reported in other studies. ${ }^{64,65,66}$

In contrast, some studies have reported low levels of mental illness knowledge amongst doctors, $15,19,67,68$ particularly in those who had little or no formal psychiatric training. It would appear that non-psychiatric doctors are, at the very least, comfortable in diagnosing common mental illnesses such as depression but feel less confident in being able to treat mentally ill patients effectively. ${ }^{69,70}$ Inadequate mental illness knowledge appears to be prevalent in medical students and nurses as well..$^{20,22}$

The findings of adequate levels of knowledge in this study may have been, in part, because of training and exposure to psychiatry in medical teaching facilities in South Africa. South African universities have established training programmes for medical and psychiatric teaching, with four of South Africa's medical schools being ranked in the top 300 best universities globally for clinical medicine. ${ }^{71}$ Another explanation is that the research questions may have been too simple and straightforward and focused only on diagnosis and symptomatology - this is a retrospective finding. As literature shows, non-psychiatric doctors reportedly have most difficulty with instituting treatment for mental illness and appropriate pharmacotherapy. Hence, there appears to be significant gaps in primary care and non-specialist doctors' knowledge of mental illness with regard to interventions. Including questions on treatment and pharmacotherapy may have yielded different, albeit more representative, results.

\section{Sociodemographic variables associated with knowledge of mental illness}

Overall, no significant associations between sociodemographic variables and mental illness knowledge could be made in any of the study groups. Significant associations were made in other studies. Younger age ${ }^{66}$ engagement in mental health training not long before participation in a research study, ${ }^{69,70}$ as well as being a family physician (compared to GPs or other specialists) ${ }^{64}$ are associated with better diagnostic and practical knowledge. Aruna et al. ${ }^{20}$ found that the level of knowledge in undergraduate medical students increased with progressive years of study, such that students in their final years had better mental health literacy than those in their first year of study. The general finding appears to be that doctors who engaged in some form of compulsory psychiatric training, over and above standard medical school teaching, have better knowledge of mental illness and are thus better able to manage psychiatric conditions.
It is noteworthy that positive attitudes towards mental illness appear to be associated with a better knowledge of mental illness and self-perceived competence in dealing with mental illness. ${ }^{55,58}$

Negative attitudes appear to be associated with a lack of mental health training and a self-perceived lack of competence in managing mental illness. ${ }^{15}$ Also, better knowledge appears to be associated with a more positive attitude. Whilst it may not be possible to discern whether better knowledge is a consequence of positive attitudes or vice versa, it seems clear that the two share a significant association and both are likely to have an important contribution towards patients receiving adequate mental healthcare. Therefore, it stands to reason that in order to reach an end goal of improved healthcare for mentally ill patients, both doctors' attitudes and mental health knowledge need to be adequately addressed.

Focusing on improving both factors (attitudes and mental health knowledge) is likely to lead to significantly better health outcomes for the mentally ill. Training of nonspecialist doctors, focused on recognition and management of mental illnesses, may contribute to reducing the stigma of mentally ill patients within healthcare services. Consequently, this may lead to an increased willingness for families and patients to seek help, leading to earlier diagnosis, better recognition of illnesses and improved outcomes. A focus on fostering positive attitudes towards mental illness in nonspecialist and primary healthcare doctors may make doctors more receptive to learning more about mental illnesses. This, in turn, may mean that doctors are willing to spend more time with mentally ill patients to determine their psychiatric symptoms and stressors and manage their illnesses better.

\section{Limitations of the study}

An important limitation of this study is selection bias. Participants in the study were selected through convenience sampling and doctors who already held positive attitudes towards mental illness may have been more likely to complete the survey compared with doctors who would have expressed negative attitudes, thereby skewing the study's findings in favour of a more positive result. Another limitation is that the questionnaire used in the study was developed for the purposes of this study only and has not been validated or used in any other study - this may affect the comparison of the study's findings to other research. As previously mentioned, the questions used to assess mental illness knowledge may have been too simplistic and easy, thereby affecting the results.

\section{Recommendations}

Although positive findings were demonstrated overall, some doctors seem to have negative attitude towards the mentally ill. Other South African samples have displayed overall negative attitude towards mental illness, which lends weight 
to the necessity of anti-stigma interventions for South African healthcare professionals. A number of stigma-reduction interventions have been researched and evaluated; these involve approaches at varying levels, including interpersonal, institutional and structural levels.

Whilst the doctors who participated in this study appear to have a good knowledge of mental illness, improving on all aspects of psychiatric knowledge in non-specialist doctors has the potential to improve care at a primary healthcare and generalist level. Several educational programmes and teaching interventions to improve mental illness outcomes at the primary healthcare level have been developed and may be of benefit. These include the WHO's Mental Health Gap Action Programme, individualised training, e-learning approaches, workshops and continuous professional development and mentoring programmes coordinated by specialists. Other interventions include increasing the length of time that medical students spend in psychiatric rotations, increasing exposure to stable patients and rehabilitative services for the mentally ill and introducing specialised and specific anti-stigma teaching into psychiatric rotations. ${ }^{47,72}$ Reducing mental illness stigma and improving mental health knowledge can be achieved simultaneously through improved and consistent education and training at an undergraduate level, as well as upskilling and continuous professional development for qualified healthcare professionals.

\section{Conclusion}

This study showed that, in spite of limitations of application of the study tool, non-specialist doctors in both state and private sectors generally held positive attitudes towards mental illness and displayed adequate levels of knowledge, particularly with respect to the symptoms and diagnosis of mental illness. Doctors working in the private sector were slightly more positive in their attitudes than state-employed doctors.

Amongst the state-employed doctors, male doctors felt more comfortable with treating physical illnesses than mental illnesses, whilst those who were practising for more than 10 years and who had no close contact with mental illness had less positive attitudes.

To the best knowledge of the researcher, no other studies looking at attitudes and knowledge of mental illness in nonspecialist doctors in South Africa have been performed. The findings of this study are important and relevant when one considers the high burden of mental illness in South Africa, as well as the prevalence of mental illness in patients consulting at the primary healthcare facilities, which are often the first port of call for seeking treatment and assistance.

\section{Acknowledgements}

The authors would like to acknowledge Professor Neville Pillay (School of Animal, Plant and Environment Sciences,
University of the Witwatersrand) for his assistance in statistical analysis. The authors also thank the clinical managers, doctors and administrators at practitioner bodies who assisted in disseminating the survey, as well as the doctors who took the time to participate in the study.

\section{Competing interests}

The authors declare that they have no financial or personal relationships that may have inappropriately influenced them in writing this article.

\section{Authors' contributions}

All authors contributed meaningfully to the study protocol and final manuscript. Y.M. wrote the study protocol, designed the questionnaire, collected the data and wrote the manuscript. M.Y.H.M. and F.Y.I. supervised the study, assisted with protocol development, and contributed to and assisted with the editing of the final manuscript.

\section{Funding information}

This research received no specific grant from any funding agency in the public, commercial or not-for-profit sectors.

\section{Data availability}

Data are available upon request from the corresponding author, Y.M.

\section{Disclaimer}

The views and opinions expressed in this article are those of the authors and do not necessarily reflect the official policy or position of any affiliated agency of the authors.

\section{References}

1. Herman AA, Stein DJ, Seedat S, Heeringa SG, Moomal H, Williams DR. The South African Stress and Health (SASH) study: 12-Month and lifetime prevalence of common mental disorders. S Afr Med J. 2009;99(5):339-344.

2. Steel Z, Marnane C, Iranpour C, et al. The global prevalence of common mental disorders: A systematic review and meta-analysis 1980-2013. Int J Epidemiol. 2014;43(2):476-493. https://doi.org/10.1093/ije/dyu038

3. Jack $H$, Wagner RG, Petersen I, et al. Closing the mental health treatment gap in South Africa: A review of costs and cost-effectiveness. Glob Health Action. 2014;7(Suppl. 1):1-11. https://doi.org/10.3402/gha.v7.23431

4. Atwoli L, Stein DJ, Williams DR, et al. Trauma and posttraumatic stress disorder in South Africa: Analysis from the South African Stress and Health Study. BMC Psychiatry. 2013;13:182. https://doi.org/10.1186/1471244X-13-182

5. Sartorius N. Stigmatized illnesses and health care. Croat Med J [serial online]. 2007 [cited 2019 Oct 19]:48(3):396-397. Available from: http://www. pubmedcentral.nih.gov/articlerender.fcgi?artid=PMC2080544

6. Thornicroft G. Stigma and discrimination limit access to mental health care Epidemiol Psichiatr Soc. 2008;17(1):14-19. https://doi.org/10.1017/S1121189X 00002621

7. Lam TP, Lam KF, Lam EWW, Ku YS. Attitudes of primary care physicians towards patients with mental illness in Hong Kong. Asia Pac Psychiatry. 2013;5(1):19-28. https://doi.org/10.1111/j.1758-5872.2012.00208.x

8. Kochaski A, Cechnicki A. The attitudes of Polish psychiatrists toward people suffering from mental illnesses. Psychiatr Pol. 2017;51(1):29-44. https://doi. org/10.12740/PP/62400

9. Mariam M, Bedaso A, Ayano G, Ebrahim J. Knowledge, attitude and factors associated with mental illness among nurses working in public hospitals, Addis Ababa, Ethiopia. J Ment Disord Treat. 2016;2(108):1. https://doi.org/10.4172/ 2471-271X.1000108 
10. Kapungwe A, Cooper S, Mayeya J, et al. Attitudes of primary health care providers towards people with mental illness: Evidence from two districts in Zambia. Afr J Psychiatry. 2011;14(4):290-297. https://doi.org/10.4314/ajpsy.v14i4.6

11. Adewuya AO, Oguntade AA. Doctors' attitude towards people with mental illness in Western Nigeria. Soc Psychiatry Psychiatr Epidemiol. 2007:42(11):931-936. https://doi.org/10.1007/s00127-007-0246-4

12. Fernando SM, Deane FP, McLeod HJ. Sri Lankan doctors' and medical undergraduates' attitudes towards mental illness. Soc Psychiatry Psychiatr Epidemiol. 2010;45(7):733-739. https://doi.org/10.1007/s00127-009-0113-6

13. Chikaodiri AN. Attitude of health workers to the care of psychiatric patients. Ann Gen Psychiatry. 2009;8:1-7. https://doi.org/10.1186/1744-859X-8-19

14. Corrigan PW, Watson AC. Understanding the impact of stigma on people with mental illness. World Psychiatry Off J World Psychiatr Assoc [serial online]. 2002 [cited 2019 Oct 24];1(1):16-20. Available from: http://www.ncbi.nlm.nih.gov/ pubmed/16946807\%0Ahttp://www.pubmedcentral.nih.gov/articlerender. fcgi?artid=PMC1489832

15. Cowan J, Raja S, Naik A, Armstrong G. Knowledge and attitudes of doctors regarding the provision of mental health care in Doddaballapur Taluk, Bangalore Rural district, Karnataka. Int J Ment Health Syst. 2012;6(1):21. https://doi. org/10.1186/1752-4458-6-21

16. Hori $\mathrm{H}$, Richards $M$, Kawamoto $Y$, Kunugi H. Attitudes toward schizophrenia in the general population, psychiatric staff, physicians, and psychiatrists: A web-based survey in Japan. Psychiatry Res. 2011;186(2-3):183-189. https://doi. org/10.1016/j. psychres.2010.08.019

17. James BO, Omoaregba JO, Okogbenin EO. Stigmatising attitudes towards persons with mental illness: A survey of medical students and interns from Southern Nigeria. Ment Illn. 2012;4(1):32-34. https://doi.org/10.4081/mi.2012.e8

18. Ganasen KA, Parker S, Hugo CJ, Stein DJ, Emsley RA, Seedat S. Mental health literacy: Focus on developing countries. Afr J Psychiatry. 2008;11(1):23-28. https://doi.org/10.4314/ajpsy.v11i1.30251

19. Wu Q, Luo X, Chen $S$, et al. Mental health literacy survey of non-mental health professionals in six general hospitals in Hunan Province of China. PLoS One. 2017;12(7):1-13. https://doi.org/10.1371/journal.pone.0180327

20. Aruna G, Mittal S, Yadiyal MB, Acharya C, Acharya S, Uppulari C. Perception knowledge, and attitude toward mental disorders and psychiatry among medical undergraduates in Karnataka: A cross-sectional study. Indian J Psychiatry. 2016;58(1):70-76. https://doi.org/10.4103/0019-5545.174381

21. Vermani M, Marcus $M$, Katzman MA. Rates of detection of mood and anxiety disorders in primary care: A descriptive, cross-sectional study. Prim Care Companion J Clin Psychiatry. 2011;13(2):e1-e10. https://doi.org/10.4088/PCC. $10 \mathrm{~m} 01013$

22. Dirwayi NP. Mental illness in primary health care: A study to investigate nurses knowledge of mental illness and attitudes towards the mentally ill. A dissertation submitted in partial fulfilment of the requirements for the degree of Masters of Arts in Research Psy [homepage on the Internet]. 2002 [cited n.d.]. Available from: https://open.uct.ac.za/handle/11427/7930

23. Dube F, Uys LN. Integrating mental health care services in primary health care clinics: A survey of primary health care nurses' knowledge, attitudes and beliefs. S Afr Fam Pract. 2016;58(3):119-125. https://doi.org/10.1080/20786190.2016.1191747

24. Nyblade L, Stockton MA, Giger K, et al. Stigma in health facilities: Why it matters and how we can change it. BMC Med. 2019;17(1):1-15. https://doi.org/10.1186/ s12916-019-1256-2

25. Knaak S, Mantler E, Szeto A. Mental illness-related stigma in healthcare: Barriers to access and care and evidence-based solutions. Healthc Manag Forum. 2017;30(2):111-116. https://doi.org/10.1177/0840470416679413

26. Henderson C, Evans-Lacko S, Thornicroft G. Mental illness stigma, help seeking and public health programs. Am J Public Health. 2013;103(5):777-780. https:// doi.org/10.2105/AJPH.2012.301056

27. John A, McGregor J, Jones I, et al. Premature mortality among people with severe mental illness - New evidence from linked primary care data. Schizophr Res. 2018;199:154-162. https://doi.org/10.1016/j.schres.2018.04.009

28. Ashworth $M$, Schofield P, Das-Munshi J. Physical health in severe mental illness. Br J Gen Pract. 2017;67(663):436-437. https://doi.org/10.3399/bjgp17X692621

29. Jones S, Howard L, Thornicroft G. 'Diagnostic overshadowing': Worse physical health care for people with mental illness. Acta Psychiatr Scand. 2008;118(3): 169-171. https://doi.org/10.1111/j.1600-0447.2008.01211.x

30. Kassam A, Papish A, Modgill G, Patten S. The development and psychometric properties of a new scale to measure mental illness related stigma by health care providers: The Opening Minds Scale for Health Care Providers (OMS-HC). BMC Psychiatry. 2012;12:62. https://doi.org/10.1186/1471-244X-12-62

31. Compton MT, Hankerson-Dyson D, Broussard B. Development, item analysis and initial reliability and validity of a multiple-choice knowledge of mental illnesses test for lay samples. Psychiatry Res. 2011;189(1):141-148. https://doi.org/ 10.1016/j.psychres.2011.05.041

32. O'Connor M, Casey L. The mental health literacy scale (MHLS): A new scale-based measure of mental health literacy. Psychiatry Res. 2015;229(1-2):511-516. https://doi.org/10.1016/j.psychres.2015.05.064

33. Evans-Lacko S, Little K, Meltzer H, et al. Mental health knowledge schedule. Can J Psychiatry. 2010;55(7):440-448. https://doi.org/10.1177/070674371005500707

34. Fujii T, Hanya M, Kishi M, Kondo Y, Cates ME, Kamei H. An internet-based survey in Japan concerning social distance and stigmatization toward the mentally ill amons doctors, nurses, pharmacists, and the general public. Asian J Psychiatr. 2018;36: 1-7. https://doi.org/10.1016/j.ajp.2018.05.017
35. Aldahmashi T, Almanea A, Alsaad A, Mohamud M, Anjum I. Attitudes towards depression among non-psychiatric physicians in four tertiary centres in Riyadh. Heal Psychol Open. 2019;6(1):2055102918820640. https://doi.org/10.1177/ Heal Psychol Open

36. Alshahrani W. A literature review of healthcare professionals ' attitudes towards patients with mental illness. Int J Med Res Heal Sci. 2018;2(1):5.

37. Nauta K, Boenink AD, Wimalaratne IK, Menkes DB, Mellsop G, Broekman BFP. Attitudes of general hospital consultants towards psychosocial and psychiatric problems in Netherlands. Psychol Health Med. 2019;24(4):402-413. https://doi org/10.1080/13548506.2018.1546020

38. Wang J, Wang Q, Wimalaratne I, Menkes DB, Wang X. Chinese non-psychiatric hospital doctors' attitudes toward management of psychological/psychiatric problems. BMC Health Serv Res. 2017;17(1):1-8. https://doi.org/10.1186/ s12913-017-2521-8

39. Eksteen HC, Becker PJ, Lippi G. Stigmatization towards the mentally ill: Perceptions of psychiatrists, pre-clinical and post-clinical rotation medical students. Int I Soc Psychiatry. 2017;63(8):782-791. https://doi.org/10.1177/0020764017735865

40. Mausling MB, Macharia M, Jordaan GP. Junior medical students' knowledge about and attitudes towards electroconvulsive therapy in a South African setting. S Afr Psychiatr. 2017;23(0):a1062. https://doi.org/10.4102/sajpsychiatry.v23i0.1062

41. Chang S, Ong $\mathrm{HL}$, Seow $\mathrm{E}$, et al. Stigma towards mental illness among medical and nursing students in Singapore: A cross-sectional study. BMJ Open. 2017;7(12): nursing students in Singapore: A cross-sectional study.
$1-11$. https://doi.org/10.1136/bmjopen-2017-018099

42. Cremonini V, Pagnucci N, Giacometti F, Rubbi I. Health care professionals attitudes towards mental illness: Observational study performed at a public health facility in Northern Italy. Arch Psychiatr Nurs. 2018;32(1):24-30. https://doi.org/10.1016/ j.apnu.2017.09.007

43. Noblett JE, Lawrence R, Smith JG. The attitudes of general hospital doctors towards patients with comorbid mental illness. Int J Psychiatry Med. 2015;50(4) 370-382. https://doi.org/10.1177/0091217415612721

44. Naeem F, Ayub M, Javed Z, Irfan M, Haral F, Kingdon D. Stigma and psychiatric illness: A survey of medical students and doctors in Lahore, Pakistan. J Ayub Med Coll Abbottabad. 2006;18(3):46-49.

45. Jury KL. The attitudes of doctors in South African teaching hospitals towards mental illness and psychiatry - A research report submitted in partial fulfilment of the requirements for the degree of Master of Medicine in the branch of Psychiatry [homepage on the Internet]. Vol. 20. 2016 [cited 2019 July 12]. Available from: http://www.sajp.org.za/index.php/sajp/article/view/664/480\%0Ahttp://ovidsp. ovid.com/ovidweb.cgi?T=JS\&PAGE=reference\&D=emed16\&NEWS=N\& $\mathrm{AN}=72323887$

46. Mavundla TR, Uys LR. The attitudes of nurses towards mentally ill people in a general hospital setting in Durban. Curationis. 1997;20(2):3-7. https://doi. org/10.4102/curationis.v20i2.1297

47. Du Preez R, Bergh A-M, Grimbeek J, Van der Linde M. Medical students' experience and perceptions of their final rotation in psychiatry. S Afr J Psychiatry. 2015; 21(1):24-30. https://doi.org/10.4102/sajpsychiatry.v21i1.641

48. Ritchie H, Roser M. Mental health [homepage on the Internet]. 2019 [cited n.d.]. Available from: https://ourworldindata.org/mental-health

49. Mata D, Ramos M, Bansal N, et al. Prevalence of depression and depressive symptoms among resident physicians: A systematic review and meta-analysis. J Am Med Assoc. 2015;314(22):2373-2383. https://doi.org/10.1001/jama.2015. 15845

50. Onyishi M, Talukdar D, Sanchez R, Olaleye AO. Prevalence of clinical depression among medical students and medical professionals: A systematic review study. iMedPub J. 2016;8:6. https://doi.org/10.21767/1989-5216.1000178

51. Ma Z, Huang H, Nie G, Silenzio VMB, Wei B. Attitude towards mental illness among primary healthcare providers: A community-based study in rural China. Biomed Res Int. 2018;2018:8715272. https://doi.org/10.1155/2018/8715272

52. Sujaritha V, Partheeban $M$, Thiviya $T$, Sowmiya M. Attitude towards mental illness among doctors and nurses in a tertiary care centre, Pondicherry, India. Int J Res Med Sci. 2017;5(7):3059-3064. https://doi.org/10.18203/2320-6012.ijrms20172987

53. Sri VC, Dempster LV. Attitude of doctors towards mentally ill in Hyderabad, India: Results of a prospective survey. Indian J Psychiatry. 2015;57(2):190-195. https:// doi.org/10.4103/0019-5545.158190

54. Ubaka CM, Chikezie CM, Amorha KC, Ukwe CV. Health professionals' stigma towards the psychiatric ill in Nigeria. Ethiop J Health Sci. 2018;28(4):483-494. https://doi.org/10.4314/ejhs.v28i4.14

55. Chandramouleeswaran S, Rajaleelan W, Edwin NC, Koshy I. Stigma and attitudes toward patients with psychiatric illness among postgraduate Indian physicians. Indian J Psychol Med. 2017;39(6):746-749. https://doi.org/10.4103/IJPSYM. IJPSYM_84_17

56. Telles-Correia D, Gama Marques J, Gramaça J, Sampaio D. Stigma and attitudes towards psychiatric patients in Portuguese medical students. Acta Med Port. 2015;28(6):715. https://doi.org/10.20344/amp.6231

57. Rojas Vistorte AO, Ribeiro WS, Ziebold C, et al. Clinical decisions and stigmatizing attitudes towards mental health problems in primary care physicians from Latin American countries. PLoS One. 2018;13(11):1-14. https://doi.org/10.1371/ journal.pone.0206440

58. Rojas Vistorte AO, Ribeiro WS, Jaen D, Jorge MR, Evans-Lacko S, De Jesus Mari J. Stigmatizing attitudes of primary care professionals towards people with mental disorders: A systematic review. Int J Psychiatry Med. 2018;53(4):317-338. https:// doi.org/10.1177/0091217418778620

59. Ucok A, Soygur $\mathrm{H}$, Atakli $\mathrm{C}$, et al. The impact of antistigma education on the attitudes of general practitioners regarding schizophrenia. Psychiatry Clin Neurosci. 2006;60(4):439-443. https://doi.org/10.1111/j.1440-1819.2006. 01529.x 
60. Winkler P, Mladá K, Janoušková M, et al. Attitudes towards the people with mental illness: Comparison between Czech medical doctors and general population. Soc
Psychiatry Psychiatr Epidemiol. 2016;51(9):1265-1273. https://doi.org/10.1007/ Psychiatry Psychiatr
s00127-016-1263-y

61. Ewalds-Kvist B, Hogberg T, Lutzen K. Impact of gender and age on attitudes towards mental illness in Sweden. Nord J Psychiatry. 2012;67(5):360-368. https:// doi.org/10.3109/08039488.2012.748827

62. Stuber JP, Rocha A, Christian A, Link BG. Conceptions of mental illness: Attitudes of mental health professionals and the general public. Psychiatr Serv. 2014 65(4):490-497. https://doi.org/10.1176/appi.ps.201300136

63. Mukherjee R, Fialho A, Wijetunge A, Checinski K, Surgenor T. The stigmatisation of psychiatric illness: The attitudes of medical students and doctors in a London teaching hospital. Psychiatrist. 2002;26(5):178-181. https://doi.org/10.1192/ pb.26.5.178

64. Al-Atram AA. Physicians' knowledge and attitude towards mental health in Saud Arabia. Ethiop J Health Sci. 2018;28(6):771-778. https://doi.org/10.4314/ejhs. v28i6.12

65. Zabihi Mahmood-Abadi H, Kayhani M, Rabi M, Mohammadi MR. A survey of knowledge and attitude of non-psychiatrists (medical specialists) treating majo depression. Thrita. 2012;1(1):30-33. https://doi.org/10.5812/thrita.4263

66. Liu S-I, Lu R-B, Lee M-B. Non-psychiatric physicians' knowledge, attitudes and behaviour toward depression. J Formosian Med Assoc. 2008;107(12):921-931. https://doi.org/10.1016/S0929-6646(09)60015-2
67. James B, Jenkins R, Lawani A, Omoaregba J. Depression in primary care: The knowledge, attitudes and practice of general practitioners in Benin City, Nigeria. S Afr Fam Pract. 2012;54(1):55-60. https://doi.org/10.1080/20786204.2012. 10874176

68. Chaudhary RK, Mishra BP, Puri D. Knowledge and practices of general practitioners regarding psychiatric problems. Ind Psychiatry J. 2009;18(1):22-26. https://doi. org/10.4103/0972-6748.57853

69. Norton JL, Pommie C, Cogneau J, Haddad M, Ritchie KA, Mann AH. Beliefs and attitudes of French family practitioners towards depression: The impact of training in mental health. Int J Psychiatry Med. 2011:41(2):107-122. https://doi org/10.2190/PM.41.2.

70. Spagnolo J, Champagne F, Leduc N, et al. Mental health knowledge, attitudes, and self-efficacy among primary care physicians working in the Greater Tunis area of Tunisia. Int J Ment Health Syst. 2018;12(63):1-15. https://doi.org/10.1186/ s13033-018-0243-x

71. Best Global Universities. Global universities search [homepage on the Internet]. U.S. News and World Report. 2019 [cited 2019 Oct 1]. Available from: https:// www.usnews.com/education/best-global-universities/search?region=africa\&subj ect=clinical-medicine\&name $=$

72. Economou M, Peppou LE, Stefanis CN, Louki E. Medical students' beliefs and attitudes towards schizophrenia before and after undergraduate psychiatric training in Greece. Psychiatry Clin Neurosci. 2012;66:17-25. https://doi.org/ 10.1111/j.1440-1819.2011.02282.x 